\title{
Prácticas culturales alternativas de un colectivo juvenil
}

\section{Adriana Zaffaroni*}

\author{
Categoría: Estudio \\ Fecha de recepción: 20 de julio de 2011 \\ Fecha de aprobación: 27 de julio de 2011
}

\begin{abstract}
Resumen
Este artículo aborda las prácticas sociales de los jóvenes desde el encuadre de la categoría jóvenes/juventudes, aunque cuestionándola como universal teórico acordado con la Red Nacional de Investigadores en Juventudes, en que no alcanzan los años de escolarización obligatoria y moratoria para participar de la condición juvenil.

Esta comunicación tiene como objetivo analizar si pueden apreciarse prácticas de resistencia, oposición y líneas de fuga en el accionar juvenil a través del caso del Centro Cultural Rodante ALPARGATA que desarrolla sus actividades en diferentes barrios de la Ciudad de Salta y en municipios linderos tales como La Caldera y Vaqueros de la Provincia de Salta, Noroeste argentino (NOA).
\end{abstract}

Palabras clave: Jóvenes, prácticas de resistencia y oposición, líneas de fuga, cultura alternativa.

\section{Summary}

This article approaches the social practices of the young persons from the setting of the category young women and men/ youths, though questioning it like universally theoretically agreeing with the Investigators' National Network in Youths, in which they do not reach the years of obligatory education and moratorium to take part of the juvenile condition.

This communication has as aim analyze if they can appreciate practices of resistance, opposition and lines of escape in to drive juvenile across the case of the Cultural Rolling Center ALPARGATA that develops his activities in different neighborhoods of the City of Salta and in such adjoining municipalities as La Caldera, Vaqueros of the Province of Salta, Argentine Northwest (NOA).

Keywords: Young people, resistance and opposition practices, getaway lines, alternative culture.

Doctora en Ciencias Sociales (UBA), Máster en Gestión y Políticas Culturales (INAP), Socióloga (UBA). Directora del Centro de Investigación de Lenguas, Educación y Culturas Indígenas (CILECI). Directora del "Pluriobservatorio de Alfabetización Académica, Prácticas Intelectuales y Capacitación Docente". Docente Investigadora de la Universidad Nacional de Salta. Vicepresidente de la Asociación Argentina de Sociología. amizaffaroni@yahoo.com.ar 


\section{Introducción}

Este artículo aborda las prácticas sociales de los jóvenes desde el encuadre de la categoría jóvenes/juventudes, aunque cuestionándola como universal teórico acordado con la Red Nacional de Investigadores en Juventudes, en que no alcanzan los años de escolarización obligatoria y moratoria para participar de la condición juvenil.

Esta comunicación tiene como objetivo analizar si pueden apreciarse prácticas de resistencia, oposición y líneas de fuga en el accionar juvenil a través del caso del Centro Cultural Rodante ALPARGATA que desarrolla sus actividades en diferentes barrios de la Ciudad de Salta y en municipios linderos tales como La Caldera y Vaqueros de la Provincia de Salta, Noroeste argentino (NOA).

El caso elegido es un grupo de jóvenes que se han reunido para "hacer, intercambiar y compartir cultura respetando la diversidad", pensado por dos estudiantes de la universidad pública de la provincia. Hoy está integrado por estudiantes, profesionales y vecinos de los barrios que se han propuesto constituirse en un movimiento alternativo de arte y cultura en Salta desarrollando su trabajo con sectores populares ${ }^{1}$.

En un principio (año 2006), este grupo de amigos se plantean el objetivo de instaurar una cultura alternativa debido a la falta de espacios y centros de concitación en la ciudad, los cuales no se identifican con los sectores populares ya que la política cultural en la provincia está orientada hacia el arte culto por un lado, y al mantenimiento de expresiones tradicionales (folklore) por otro. La génesis del grupo es una primera "fiesta" para que los jóvenes pudieran compartir y participar en un lugar de encuentro donde cada uno desde lo que sabe hacer, trate de compartirlo y a la vez

\footnotetext{
${ }^{1}$ Entrevistas grupales e individuales realizadas a los integrantes del colectivo Alpargata incluyendo a sus fundadores, realizadas en la Ciudad de Salta durante el año 2007/2008.
} 
enriquecerse con lo nuevo, dejando de lado las formas de diversión impuestas como "únicas" por el sector elitista de la sociedad y unificándose por un mismo sentimiento de rechazo ante éstas.

Los fundadores son jóvenes de sectores medios empobrecidos que tomaron contacto entre sí a través de la música. Son músicos y se reunían "para compartir música" desde un interés personal, buscaban en la Ciudad de Salta espacios donde hacer música, ser escuchados y escuchar a otros grupos. Juntos se dedicaron varias semanas a esa búsqueda pero no lograron encontrar ese lugar; a partir de allí expresan: "empezamos a recorrer todos los lugares que conocimos y en ninguno pudimos engancharnos, ni en la Balcarce ni en los otros van, ni en ningún lado encontramos un lugar que nos contenga", "estábamos excluidos del entorno", y resolvieron: "bueno, hagamos nuestro propio lugar para entretenernos" ${ }^{\prime \prime}$.

La inquietud fundadora del grupo fue encontrar espacios para "entretenerse", "para hacer música y ser escuchados". El origen es señalado por los fundadores como un experimento para generar un espacio alternativo, no era un proyecto con las características que luego tuvo. En este sentido enfrentan la racionalidad del sistema al invertir la relación idea-proyecto por la de experimento-vivencia-experiencia-proyecto.

La resistencia desde las prácticas juveniles, individuales y colectivas, inconscientes o autodefinidas, puede vehiculizar diversas formas de encarar sus desacuerdos con las relaciones sociales en que están inmersos. La misma puede ser encarada como un cuestionamiento a los adultos, a sus prácticas y discursos; como una crítica a la sociedad vista como portadora de antivalores, con diferentes niveles de reflexión sobre posibilidades de

\footnotetext{
2 Los párrafos textuales fueron extraídos de las entrevistas en profundidad a los fundadores e integrantes del Colectivo. Esta información fue complementada por observaciones de las reuniones del grupo y la participación en los eventos que ellos presentaban.
} 
cambio o como un rechazo a cualquier otro sector joven que no viva dentro de su propia subcultura juvenil. Es decir, considerar a los "otros" como antagonistas. De acuerdo a nuestro posicionamiento epistemológico que parte de la necesidad de un conocimiento situado y de las políticas del lugar resulta necesario habilitar la reflexión acerca de los procesos vividos en el país y en la región que contextualizan la presente investigación.

El conocimiento situado está relacionado con el concepto de "lugar" y es abordado desde varios puntos de vista, desde su relación con el entendimiento básico de ser y conocer, hasta su destino bajo la globalización económica y, también, en la medida en la que sigue siendo una ayuda o un impedimento para pensar la cultura. Para algunos, la ausencia de lugar es una "condición generalizada de desarraigo", y si bien forma parte de la condición moderna, significa en muchos casos, como en el de los desplazados, exiliados y refugiados una experiencia dolorosa. Sin embargo el lugar ha sido ignorado por muchos pensadores, y las teorías de la globalización han marginado la cuestión "del lugar" (Escobar, 2005: 2003).

\section{Cultura popular e ilustrada en América Latina, Argentina y Salta}

En América Latina puede hablarse de una verdadera confrontación entre culturas, que ha tenido aristas dramáticas ya que constituyó un genocidio que ha sido caratulado como encuentro de culturas por la historia oficial. El fenómeno en general fue visto y narrado desde los europeos a través de sus cronistas de Indias. Sin duda mucho se ha escrito y teorizado acerca del mestizaje como matriz cultural, del sincretismo, de la heterogeneidad y de las hibridaciones (Segato, 2007; Briones, 2005; Grimson, 2004; García Canclini, 1990).

El filósofo argentino Rodolfo Kusch ha propuesto una doble comprensión (que implica una doble forma de situarse), necesaria 
para acceder a nuestra cultura. La dualidad entre sujeto pensante y sujeto cultural en América (Kusch, 1976), hace que debamos acceder a ella considerando dos presiones: la del hedor y la de la pulcritud; la del mero estar y la del ser alguien (Kusch, 1986). Por un lado, lo deseable: el progresismo civilizatorio, lo racional, lo fundante; por el otro, lo indeseable, el primitivismo bárbaro, lo irracional, lo arcaico, lo demoníaco. El hombre latinoamericano vive esta dualidad en la forma de dos presiones: la seducción por ser alguien (una libertad sin sujeto, pero rodeada de objetos) y el miedo a dejarse estar (una amenaza con la fuerza de lo bárbaro: el miedo a «ser inferior»).

Las reflexiones de Jorge Huergo y María Belén Fernández (2000) nos indican que preexiste en la historia cultural postcolombina latinoamericana el mito de la pulcritud, según el cual la civilización (la «pulcritud») y el progreso deben remediar la barbarie y el atraso (el «hedor»). Como contrapartida de este emprendimiento de mutación del ethos popular, el «hedor», lo que hay de profundo y creativo propio, fagocita la «pulcritud» y su «patio de objetos». La necesidad de combatir el hedor de los objetivos y razón de ser a la escuela y su escolarización que ha sido pensada como uno de los factores determinantes en este remedio de la barbarie y el atraso, o para la «miseria moral» y la «ignorancia» (Saviani, 1990), o en la mutación del ethos popular.

Esta dualidad señalada por Kusch se hace presente a través de los conceptos de civilización y barbarie en Domingo Sarmiento, representando al «espíritu» y la «naturaleza» respectivamente (Sarmiento, 1964). El gaucho, el indio y su cultura están asociados a la naturaleza, son naturaleza.

En cambio la sociedad civilizada, que implica el progreso material (modernización) y la perfección moral, debe construirse contra su propia naturaleza, con la idea de sustitución y no de complementación. En el esquema sarmientino, la relación entre el sujeto pedagógico y la Nación tiene un claro sentido "positivo» (el positum de la civilización es Europa) y no proviene del rescate 
de lo propio. Más bien la propuesta es encarar lo propio y, trocándole su destino, proyectarlo hacia la civilización. En este marco, las masas populares son vistas como hordas indisciplinadas, y la escolarización es una batalla contra la barbarie. La contradicción está en que la escolarización (en la teoría) pretende la participación de los sujetos en el sistema sociopolítico (Sarmiento, 1949); los mismos sujetos que ella contribuye a eliminar (en la práctica). Este sistema escolar legitimado en las bases y criterios anteriormente señalados excluye al diferente.

Si la práctica cultural es la acción del sujeto a partir de modos en que operan sistemas de producción y consumo que han sido organizados por el sistema capitalista como medio de distribución de bienes simbólicos y materiales (Bourdieu, 1984), los ámbitos determinados socialmente distribuyen los gustos como "gusto legítimo o burgués", "el gusto medio" y "el gusto popular".

En Salta ${ }^{3}$ persiste la distinción entre Arte alto o de elite y el Arte popular, es un mecanismo de diferenciación desde el cual también se conformaría la "identidad" de los artistas y los jóvenes. La Capital Salteña -Ciudad de Salta- se constituye hoy como una ciudad simulacro. La Plaza Central es un verdadero escenario que se contradice con la vida cotidiana de la mayoría de pobres que la habitan. Las diez cuadras que rodean a la plaza principal 9 de Julio, albergan miles de turistas para formar parte

\footnotetext{
3 Salta fue fundada el 16 de abril de 1582 por Hernando de Lerma, desde las fuentes oficiales de la provincia su nombre podría provenir de SAGTA, voz aymara que significa "muy hermoso"; SALLATA, también del aymara cuyo significado es Salla: peñas, y Ta: lugar, y SAYTA, pascana o descanso. Lo cierto es, que juntando estos vocablos podríamos decir "Hermosa región de serranías en cuyo fértil valle se encuentra descanso". También puede sumarse a este significado, que el lugar fue habitado por los Sagtas, nombre de una de las comunidades indígenas perteneciente a la cultura Diaguita. Históricamente Salta era el paso obligado en el camino al Alto Perú, y en este sentido fue más conocida como el Puerto Seco, ya que en pleno corazón del Valle de Lerma se estableció la "feria de mulas" más importante de la época colonial. Conocido este lugar como Sumalao, allí se juntaban más de $70 \mathrm{mil}$ cabezas de bueyes provenientes del centro y sur del país, siendo este el punto de distribución para los países de Bolivia, Chile, Perú y Paraguay.
} 
de un proyecto global exclusivo, mientras el modelo económico social neoliberal aumenta las fragmentaciones y exclusiones.

La siesta salteña, el encuentro popular, los eventos sociales, como también el silencio ante el deterioro de las condiciones de vida de mucho de los salteños, son parte de un sistema de valores y creencias distantes del centro de la ciudad o de quienes planifican el futuro, con lo cual, la "tradición" se usa y se monta como espectáculo para ser mostrada con curiosidad al forastero, pero se vive lo propio, la cotidianidad y las costumbres "pueblerinas" de puertas adentro y, a veces, al margen de la vida cultural oficial, construyendo y sosteniendo espacios que se conectan de otras maneras pero que son muy eficientes en tanto funcionan como comunicación entre iguales, "entre sectores marginados" (Coronel, 2007).

El arte culto tiene un perfil eurocéntrico y está centrado fundamentalmente en las actividades de la Orquesta Sinfónica de Salta que excluye la participación de los sectores populares, más allá de los conciertos en los barrios. Es necesario revisar desde las prácticas culturales las concepciones sobre el arte, la música, los artistas, la cultura, lo popular y lo masivo. La observación crítica debe ser orientada desde la nueva mirada de los estudios decoloniales (Lander, 2000).

\section{Acuerdos, desacuerdos y resistencias de los jóvenes en un contexto neoliberal}

Dentro del neoliberalismo, cosmovisión política y social hegemónica, la concepción del mercado como un campo de posibilidades que serán aprovechadas en tanto la destreza y el esfuerzo individual logren la "inserción" en él, hace que la sociedad atribuya la responsabilidad a la persona, al individuo, lo que implica que si no se integra es su culpa, por cuanto no utilizó bien las "oportunidades ofrecidas" o no tiene voluntad para hacerlo. Como ejemplo, menciono que la sociedad a través del mercado se apropia 
de los símbolos de la juventud, de sus estilos, y los incorpora al mercado como objetos masivos. De esta manera logra la universalización del símbolo, a través de la cual lo que era el vínculo de identidad de un grupo marginado particular pierde todo valor distintivo, debido a que pasa a ser de uso general; con lo que ocurre una inversión del significado del símbolo al separarse del grupo marginado que lo creó. En este caso el símbolo niega su contenido (Sarlo, 1994).

De tal manera el sistema expropia a sus sectores menos favorecidos, no sólo una plusvalía económica, sino una plusvalía cultural y simbólica.

Las actitudes de desacuerdo con las relaciones sociales y las instituciones, tienen características diferentes de acuerdo al sector de proveniencia, al mismo tiempo las oposiciones al sistema y sus instituciones pueden ser más o menos profundas. Muchas veces esta contradicción queda reducida en el ámbito social, únicamente al enfrentamiento con personas, evitando así la característica globalizante que la dominación asume, constituyéndose en oposiciones. Alternativas juveniles desde los sectores poblacionales se evidencian en las resistencias y oposiciones al deber ser capitalista.

En el primer sentido enfatizado, vemos que la actitud ante la falta de trabajo de jóvenes provenientes de una familia acomodada económicamente, no será la misma que la de una o un joven de una familia en la pobreza o la indigencia, en que la urgencia de comer es dramática dado el peligro de muerte. Tanto unos como otros, sufrirán la frustración de no tener un espacio laboral, sin embargo la precariedad del joven pobre le obliga a enfrentarla de una manera distinta a quien podrá esperar alternativas de trabajo ventajosas, sin la urgencia de no tener para comer. Dicho así, la posición de resistencia a la situación de "desocupación y cesantía" será actuada en forma diferente por cada joven según su realidad, y constituye el primer condicionamiento para la profundidad con que se enfrentará a su problemática. 


\section{Alternativos y utópicos}

La resistencia, desde las prácticas juveniles, individuales y colectivas, inconscientes o autodefinidas, como lo señalé anteriormente, puede vehiculizar diversas formas de encarar sus desacuerdos con las relaciones sociales en que están inmersos.

Aprecio el carácter social y el horizonte utópico que tienen los procesos de resistencia que pueden darse en el ámbito social, cultural o educativo. Esas características democráticas y solidarias marcan desde estos criterios, una nueva manera de hacer política; es alternativo en cuanto se lo entiende como alternativa efectiva de la organización capitalista de la existencia, y utópico, o sea, orientado por un concepto trascendental que surge desde el rechazo a la inautenticidad u opresión efectivamente sentida en sus condiciones de existencia y que se propone como referente para una acción transformadora radical de esas condiciones de muerte en condiciones de vida (Gallardo, 1991).

Entendida de este modo la resistencia y oposición juvenil, en el caso presentado: Centro Cultural Alpargatas, una superación de la mera sobrevivencia, del conformismo, del individualismo, de la falta de propuesta, de la cooptación, para aparecer como un accionar complejo, cotidiano, que adquiere perspectivas estratégicas. Su accionar manifiesta resistencia a las prácticas políticas que han privilegiado el sectarismo, el vanguardismo, el dogmatismo, la corrupción y que, al mismo tiempo, favoreció la tendencia a la desagregación individual y colectiva. En síntesis, la resistencia que este colectivo presenta es otra forma de enfrentarse a una situación social específica, proponiendo una convivencia con otros criterios y valores.

El análisis en profundidad de este caso nos permite deslindar a la resistencia de la oposición, siendo esta última una manifestación de rechazo al sistema pero que no busca su transformación y tampoco desarrolla una propuesta que permita orientarla por un horizonte de vida. 
La etnografía realizada para conocer el accionar del grupo a través de entrevistas en profundidad, observaciones y participación en sus actividades, me permiten distinguir nudos de tensión que generan acciones de resistencia. Del análisis de las entrevistas en profundidad surgen las siguientes categorías respecto de la sociedad a la que se enfrentan y frente a la que resisten.

La primera fiesta donde se logra visibilizar el grupo contó con la presencia de malabaristas, capoeiras y jóvenes que practican hip-hop (con letras de protestas sociales), músicos y cantantes, y pudieron cumplir el objetivo de "cohesionar una diversidad de gustos, ritmos, con el principal y único objetivo de compartir", es decir: se estableció una comunión en la diversidad. La categoría que emerge es la necesidad de estar juntos en la diversidad fuera de las reglas del mercado, en oposición a la oferta de la calle Balcarce ${ }^{4}$.

Los jóvenes integrantes de este Centro Cultural rodante manifiestan en una de las entrevistas que todo esto comenzó a partir de la "incomodidad que los unía en un sentimiento de incumplimiento con un compromiso social muy presente en la vida de cada uno". Por lo cual, hacer una fiesta que terminaba en una noche les pareció un objetivo individualista y pensaron en un objetivo "más social".

Su indignación y resistencia se motoriza frente a la falta de coherencia entre los valores enunciados en los discursos que no se corresponden con la práctica concreta de quienes los preconizan; hoy en día no se respetan los valores, esto puede verse a

\footnotetext{
${ }^{4}$ En la noche de los jóvenes salteños ha cobrado, desde el año 2001, una significativa y creciente importancia el circuito Balcarce, al igual que en otras provincias, por ejemplo en Córdoba, "la Rondo". En este escenario nocturno los jóvenes (y los adultos) tienen una gran oferta de pubs a los que pueden acceder, como así también a consumos determinados de bebidas alcohólicas y en algunos casos comidas. En definitiva el espacio y el consumo que se elija siempre va de la mano con el poder adquisitivo que se posea. (Ver Escenarios nocturnos y consumos culturales de los jóvenes salteños. Revista Oficios Terrestres $\mathrm{N}^{\circ} 24$. UNLP).
} 
través de las instituciones, los dirigentes (de distinto tipo y nivel) y los adultos. Prima la mentira y la hipocresía. Al mismo tiempo, la sociedad adulta es incapaz de generar un cambio social, en ellos hay signos de acomodo y funcionalidad que aseguran su reproducción. A diferencia de otras generaciones, señaladas como generaciones militantes (del 60' y 70'), que intentaron cambiar la realidad. Señalan que la familia no los preparó para la realidad sino que les mintió, este reclamo se dirige a otros adultos significativos como: padre, madre, profesores, dirigentes religiosos, sociales y/o políticos.

Apuestan a:

- La necesidad de estar juntos en la diversidad fuera de las reglas del mercado, en oposición a la oferta de la calle Balcarce.

- "Caminar y no quedarse quietos", al sinónimo del "hacer para la transformación", además porque la alpargata la puede usar cualquiera, es decir, "uno se pone la alpargata y somos todos iguales en la diferencia".

- Construir una cultura democrática, es decir: no imponer la cultura de los sectores elitistas a los sectores marginales, sino "crear una cultura entre todos".

- Compartir la "cultura", cohesionando una diversidad de gustos, ritmos, con el principal y único objetivo de dar y recibir, dejando de lado los intereses comerciales y publicitarios. Y superando la limitación que presentan los grupos que difunden la cultura elitista hoy en día, como resultado de la marginalidad a partir del desarrollo modernizador en una sociedad, donde el acceso a los beneficios está desigualmente repartido.

- "La cultura no se compra ni se vende, se comparte", intentando "plantar un semillero en un lugar y en otro", y así dejar las "huellas" y un centro cultural funcionando. Instalar un centro cultural funcionando en cada barrio.

- "Alpargata no hace asistencialismo". 
- Participan de la movida contra hegemónica por el tema de los murales callejeros y su autoría, con batucadas y arte callejero.

- También se plantearon y se plantean como objetivo un proyecto que tiene que ver con la enseñanza de instrumentos autóctonos, como el sicus; instalar un taller de fabricación de títeres y acompañar a quienes deseen realizar sus primeras obras, actividades que están realizando.

Llegando a la conclusión de que la oferta cultural estatal no atendía la demanda social es que el Centro Cultural Alpargatas empezó a definir criterios para trabajar para la comunidad.

Otro elemento destacable es "la creativa bola de nieve" categoría que se consolidó en el análisis, cada nueva actividad generaba otras que se iban fortaleciendo y acercando nuevas personas a la propuesta, así llegan a Atocha, Municipio de La Caldera, Municipio de Vaqueros, San José. A estas demandas sumaban los títeres en la Biblioteca, los videos en los colegios y el trabajo en el B.S.P.A. (Bachillerato Salteño para Adultos).

Alpargata tiene el deseo de participar, entonces existe un sentir con la gente que es recíproco. La idea fuerza es compartir, Alpargata no va a enseñar nada, no quiere enseñar nada, asimismo sienten que no están capacitados para ir a enseñar nada; en todo caso expresan: "estamos más capacitados para ir a aprender de ellos que ellos de nosotros", "entonces vamos a compartir lo que yo tengo, lo que yo soy, con lo que ellos tienen y lo que ellos son y en eso se va armando la cuestión".

\section{Despolitización/desinstitucionalización}

Aporta García Canclini (2006) que estamos viviendo algo más radical que la despolitización, se trata de una desintitucionalización. Muchos jóvenes no están interesados en tomar iniciativas de transformación estructural en la organización social. Entonces se produce un doble desencuentro entre instituciones guberna- 
mentales que tienen por tarea ocuparse de los jóvenes, proveer lo que el mercado laboral no ofrece, lo que la familia desatiende o lo que la escuela deja de dar, y jóvenes que no se sienten del todo descontentos con todo este desorden.

Estos núcleos de tensión no son un problema generacional, ni un mal biológico de jóvenes contra adultos o viceversa: son las manifestaciones cotidianas de una estructura social que se organiza en función de su reproducción de muerte y sacrificio, oprimiendo a adultos y jóvenes. No existe en los jóvenes un cuestionamiento a la existencia de la familia como tal, sí a los estilos y patrones de conducta que a ella le han sido asignados.

El imaginario juvenil porta elementos que permiten visualizar la posibilidad de establecer estilos de relaciones dignas que ayuden, en conjunto, a hacer frente a los embates que día a día atenían contra todos y todas, y de vivir dentro de la familia relaciones respetuosas de las opciones individuales y colectivas. Al pensar y trabajar en la construcción de una sociedad alternativa, es preciso considerar este aspecto. La resistencia y los procesos de oposición de los jóvenes deben ser entendidos como la tensión permanente entre crecer hacia lo que desean ser-hacer y ser lo que la sociedad quiere que sean mediante la internalización de estereotipos y en medio de la falta de posibilidades (Monsivais, 2005).

La resistencia juvenil se muestra como expresión de diferentes sectores sociales. La existencia de estas manifestaciones juveniles muestra que el carácter de sobreadaptación definitiva que intenta el imaginario neoliberal no consigue su objetivo. La existencia de la esperanza como horizonte y motivación, es fiel muestra de que los jóvenes están empeñados en transformar estas situaciones de injusticia social en un estilo de relaciones que dignifique al género humano, en su relación entre sí y con el medio ambiente. Mostrando desde su fuerza, espontaneidad y capacidad de soñar, aportes insustituibles para el "hacer-hacernos" en un proceso de cambio.

Este grupo de jóvenes parece haber escapado del concepto trampa de la globalización y sus consecuencias que se evidencian 
en las narrativas político-culturales y de ciudadanía que representan el deslumbramiento del campo cultural por la hegemonía económica que se erige como episteme.

La resistencia del Colectivo Alpargatas es resistencia a la mercantilización de la cultura y a la contaminación del vínculo con la gente a través del asistencialismo. Este posicionamiento marca una diferencia con la generalidad de las prácticas juveniles. Esto me lleva a pensar las diferencias sobre una dimensión filosófica -tal como lo plantea Ana María Fernández- poniendo en cuestión el ser de la diferencia y, por lo tanto, la configuración de identidades en la modernidad. Alpargata aborda la diferencia en relación al rechazo de los valores globales y la lógica de mercado, lo que se manifiesta en diferentes prácticas de oposición y líneas de fuga. Sin duda desde la dimensión de una nueva política proponen "hacer nuestra revolución"; apuesta que pone en crisis la efectividad en la construcción de igualdad por parte de las democracias representativas. Aprecio que Alpargata no desafía desde la negatividad, sino desde "formas afirmativas de resistencia y formas resistentes de afirmación" (Huyssen, 1987).

\section{Conclusión}

Los cuatro años de experiencia del Centro Cultural Rodante Alpargata me permiten señalar que los procesos de resistencia y las líneas de fuga, son posibles cuando existe:

- Un agruparse con otros y otras, especialmente con quienes tienen semejanzas (de edad, de intereses, de historias, de ideas, cercanía territorial, de proyectos), buscando así resistir a la desagregación y construir comunidad desde lo cotidiano. Concretando la política de lo afectivo o afectual, tal como lo plantea Maffesoli (2005).

- La presencia de valores que los lleva a enfrentarse a todo lo que signifique hipocresía y transar en valores (amistad, fidelidad, verdad, justicia) que se definen como válidos dentro de los sectores juveniles. 
- Apreciar opciones y sueños detrás de los cuales se movilizan y que les permiten resistir para avanzar en la utopía de una sociedad de hombres y mujeres con libertad e igualdad.

Alpargata es un experimento para generar un espacio alternativo que invierte la relación idea-proyecto por la de experimentovivencia-experiencia-proyecto.

La necesidad de un colectivo autónomo, capaz de pensarse y accionar por sí mismo, permite y habilita el despliegue de la autonomía y de procesos de autogestión orientados a cambiar aquello con lo que no se coincide, proponiendo objetivos y metas que los ubican como protagonistas en el juego social.

El accionar del Colectivo facilita destacar las posibilidades del espacio artístico como territorio de protagonismo juvenil. En él, los jóvenes muestran sus producciones audiovisuales, sus proyectos y sus sentires a través de diferentes expresiones: murales, títeres, fabricación de instrumentos, poesía, música, entre otros; algunas de creación e implementación colectiva como la música y los murales callejeros. La libertad que implica esta creación permite apreciar una ciudadanía cultural con apropiación de espacios y sentidos que crece por fuera de las políticas del Estado.

El caso representa la posibilidad de otros mundos juveniles, forjados en la vivencia local y en el escenario de los barrios, alejando a los sujetos de las representaciones transnacionales que homogeneizan en la lógica y la dinámica del mercado a través de modas, formas musicales y marcas, es decir, dentro de la lógica del consumo que provee referentes identitarios que posibilitan agenciamientos colectivos (Escobar, 2007).

En el noroeste argentino la gran mayoría de las y los jóvenes no acceden a los productos de las industrias transnacionales y los productos que ellos generan tienen mucha dificultad para circular y ser conocidos. En este sentido, el acceso a internet es diferenciado y desigual, estimado el nivel de conectividad en un $12 \%$ sobre el total de los jóvenes. 
Lo que he denominado focos de resistencia o líneas de fuga tienen que ver con procesos de subjetivación que no deben ser confundidos con aquellos constructores de la emergencia de un sujeto personal. La comprensión de la acción de los jóvenes a través de esta mirada teórica los ubica en modos de individuación tanto particular como colectiva, que logran atravesar líneas de poder mediante el pliegue de la fuerza sobre sí misma, logrando atravesar las fronteras de dominación, reorientando su vida y escapando de las instituciones.

Es pertinente aclarar que los cuerpos juveniles tienen la cualidad y posibilidad de alojar tanto prácticas de dominación como de resistencia, y así lo expresa Ana Ma. Fernández (2007: 262): "cada cuerpo se produce y reproduce en el complejo anillado de múltiples marcas" habilitando la posibilidad de líneas de fuga, de oposición y/o resistencia hacia el modelo social impuesto, posibilitando nodos de resistencia y a veces de creación colectiva, todas ellas constructoras de subjetividad.

No se trata, en el caso presentado como práctica de resistencia, de la posibilidad de hablar y denunciar, sino de hacer una política cultural desde los barrios. En esta tarea de comprensión del accionar juvenil, apreciamos las formas colectivas de toma de decisión y las propuestas grupales en un contexto caracterizado por el individuo y su individualidad, en una apuesta al nosotros que desdibuja el aporte individual para apoyar una práctica colectiva que también es autogestionaria (Bonvillani, 2009; Cubides, 2009; Reguillo, 2005; Escobar, 2007).

Asimismo es posible apreciar en el Colectivo Alpargata la construcción de diferentes mediaciones que lo enlazan con grupos, organizaciones y comunidades, evidenciada en el Proyecto de Murales para la Ciudad de Salta de julio de 2010, donde participan artistas plásticos, músicos y organizaciones de todo tipo que guardan cercanía de propósitos con el colectivo. De ella participan además organizaciones que han sido apoyadas en otros momentos por Alpargata, alcanzando de este modo a sectores 
más amplios de la población donde encuentran otras formas de cooperación, de reconocimiento y alianza para impulsar otros proyectos.

La clara orientación a poner en marcha procesos participativos en los barrios y comunidades se complementa con la necesidad de lograr un empoderamiento de los vecinos que contribuyen a su autonomía cultural.

Las acciones que despliega este grupo juvenil se pueden apreciar en letras de canciones, grafitis, obras de teatro, artesanías, marchas, acciones pedagógicas liberadoras de la creatividad y también en los blogs.

El conjunto de las acciones y propuestas mencionadas les han permitido organizarse y construirse como colectivo en oposición al individualismo, realizar una apuesta a la no guetización y apoyar la realización de proyectos comunes con los barrios, generando experiencias que reivindican la diferencia, la heterogeneidad y los estilos de vida.

El trabajar en los barrios, hacer cultura con los vecinos, coloca su accionar en una práctica decolonizadora respecto de la tradicional segmentación y jerarquía que atraviesa a la sociedad salteña, heredada de la época colonial, revalorizando los saberes y talentos de los sectores populares y la riqueza de la diversidad.

Este accionar colectivo, lejos de violentar subjetividades modelando conciencias busca el autodescubrimiento, la creatividad, la autonomía, los diferentes tiempos y ritmos, la participación como punto de llegada de muchas actividades planeadas en conjunto que construyen al grupo como lugar de reconocimiento y de construcción de subjetividades.

Los estudios de juventud muestran la resignificación de lo político que actualmente se expresa por canales estéticos y artísticos, y en la cotidianidad social tal como lo plantean Roxana Reguillo (2000), Roberto Escobar et al. (2004) y Cubides (2009). 
Alpargata no es un proyecto diseñado en etapas sino que es la fuerza de un colectivo juvenil que se alimenta de la pasión de cada uno de sus miembros, que no tiene una racionalidad planificada, que simplemente camina, aprende, se forma y sigue caminando.

\section{Bibliografía}

Bonvillani, Andrea (2009): “Jóvenes cordobeses: una cartografía de su emocionalidad política", en: Revista Nómadas N³2. Bogotá, Universidad Central-IESCO.

Bourdieu, Pierre (1984): Distinción: A Social Critique the Judgement of Taste. Trans Nice. London, Rotledge.

Briones, Claudia (2005): Cartografías argentinas. Políticas indigenistas $\mathrm{y}$ formaciones provinciales de alteridad. Buenos Aires, Antropofagia.

Coronel,M. (2007): La subjetividad del artista músico en Salta capital. Tesis de Licenciatura en Arte. Universidad Nacional de Salta.

Cubides, Humberto (2009): “Trazos e itinerarios de diálogos sobre política con jóvenes contemporáneos de Bogotá", en Revista Nómadas, $n^{\circ}$ 32. Bogotá, Universidad Central-IESCO.

Escobar, Arturo (2005): “Otros mundos (ya) son posibles: autorganización, complejidad y culturas postcapitalistas", en: Mas allá del tercer mundo, globalización y diferencia. AAVV. Bogotá, Popayán ICANH/Universidad del Cauca.

AAVV (2003): "Mundos y conocimiento de otro modo. Programa de investigación de modernidad/colonialidad latinomericana", en Revista Tabula Rasa ${ }^{\circ} 1$.

Escobar, Manuel (2007): “Jóvenes contemporáneos ¿Singularidades nominadas, diferencias incluidas y resistencias emergentes?", en Zuleta et al. (ed.), ¿Uno solo o varios mundos? Bogotá, Siglo del Hombre.

Fernández, Ana María (2008): Políticas y subjetividad. Asambleas barriales y fábricas recuperadas. Buenos Aires, Biblos.

Fernández, Ana María (2005): “Desde la diferencia a la diversidad. Género, subjetividad y política", en Fernandez Ana María: Uno solo o varios mundos posibles. Colombia, Siglo del Hombre. 
Gallardo, Helio (1991): "Notas para contribuir a una discusión sobre nuevos actores sociales", en Revista Pasos, $n^{\circ} 36$. San José, DEI.

García Canclini, Néstor (2006): Diferentes, desiguales y desconectados. Mapas de la interculturalidad. Barcelona, Editorial Gedisa.

García Canclini, Néstor (1990): Culturas híbridas. México, Grijalbo.

Grimson, Alejandro (2004): "Fronteras, naciones y región", en Foro Social de las Américas. Quito, Ecuador.

Huergo, Jorge y Fernández, María Belén (2000): “Cultura escolar/cultura mediática", en Revista Intersecciones. Bogotá, Universidad Pedagógica Nacional.

Huyssen, Andreas (1987): “Guía del postmodernismo", en Revista Punto de Vista $n^{\circ} 29$.

Kusch, Rodolfo (1986): América profunda. Buenos Aires, Bonum.

Kusch, Rodolfo (1976): Geocultura del hombre americano. Buenos Aires, García Cambeiro.

Lander, Edgar (2000): “¿Conocimiento para qué? ¿Conocimiento para quién?", en La colonialidad del saber, eurocentrismo y Ciencias Sociales. Perspectivas Latinoamericanas Lander (Comp.). Buenos Aires, Flacso.

Maffesoli, Michel (2005): El tiempo de las tribus. Madrid, Icaria.

Monsivais, Carlos (2005): “Tú, joven, finge que crees en mis ofrecimientos", en Revista Nueva Sociedad n 200. México.

Reguillo, Rossana (2005): Horizontes fragmentados, comunicación, cultura, pos política. El (des) orden global y sus figuras. Méxi$\mathrm{co}$, Iteso.

Sarlo, Beatriz (1994): Escena de la vida posmoderna. Buenos Aires, Ariel.

Sarmiento, Domingo (1982): Facundo. Civilización y barbarie. Madrid, Hyspamérica.

Segato, Rita (2007): La nación y sus otros. Raza, etnicidad y diversidad. Buenos Aires, Prometeo.

Zaffaroni, Adriana y equipo de investigación (2008): El futuro a través de la mirada joven en Salta. Ciudad de Salta y municipios adyacentes: Cerrillos, Vaqueros, La Caldera y San Lorenzo, a partir de sus particulares culturales. Salta, Milor. 